\title{
INHALTSVERZEICHNIS
}

\section{RICHTER, J.}

Untersuchungen über die Himbeermosaikkrankheiten im Gebiet der Deutschen Demokratischen Republik - II. Versuche zur Differenzierung des Himbeermosaiks . . . . . . . . . . . . . . . . . . . . . . .

BECKER, M.

Oxalsäurebildung in Spinat (Spinacia oleracea L.) in Abhängigkeit von der Stickstoffdüngung . . . . . . . . . . . . . . . . . . .

SCHMAdlak, J., und H. VölKel

Untersuchungen über vegetativ vermehrbare Apfelunterlagen - Verhalten und Leistung auf dem Mutterbeet 